\title{
Synaptic Organization of Claustral and Geniculate Afferents to the Visual Cortex of the Cat
}

\author{
Simon LeVay \\ Robert Bosch Vision Research Center, Salk Institute for Biological Studies, San Diego, California 92138
}

\begin{abstract}
Claustral and geniculate afferents to area 17 were labeled by anterograde axonal transport of peroxidase-conjugated wheatgerm agglutinin, and examined in the electron microscope. $\Lambda$ peroxidase reaction protocol that led to labeling in the form of minute holes in the EM sections was used. Both types of afferents formed type 1 (presumed excitatory) synapses exclusively. In agreement with previous reports the great majority of geniculate afferents to layers 4 and 6 contacted dendritic spines. The claustral afferents to layers 1 and 6 also predominantly contacted spines. In layer 4, however, claustral afferents contacted spines and dendritic shafts about equally. The results suggest a substantial claustral input to smooth-dendrite cells in layer 4 , which are thought to be inhibitory in function. This may be the circuit by which the claustrum helps to generate end-stopped cortical receptive fields (Sherk and LeVay, 1983).
\end{abstract}

The claustrum is a nuclear mass in the basal forebrain that is reciprocally and topographically connected with the cerebral cortex (Carman et al., 1964; Carey et al., 1979; Kievet and Kuypers, 1975; LeVay and Sherk, 1981a; Mettler, 1935; Narkiewicz, 1964; Norita, 1977; Olson and Graybiel, 1980; Riche and Lanoir, 1978; Whitlock and Nauta, 1956). An intriguing feature of the connections between the 2 structures is that they are organized, not on a continuous point-to-point basis, but by function. Thus there is one part of the claustrum-in the cat, the dorsocaudal portion of the nucleus - that contains a single, orderly map of the visual field (LeVay and Sherk, 1981b). Projections from several, perhaps all, the retinotopically organized visual cortical areas converge onto this region, and it in turn projects divergently back to them. Other portions of the claustrum serve auditory, somatosensory, limbic, and perhaps motor functions.

Although these functional subdivisions of the claustrum are crowded close to one another without visible borders, there is no evidence for connections between them, and physiologically the various modalities appear to remain as separate from each other in the claustrum as they are in the cortex (Olson and Graybiel, 1980; Sherk and LeVay, 1981; but see Spector et al., 1974). What, then, is the reason for the existence of the claustrum? Evidence bearing on this question comes from a study in which response properties of neurons in the cat's primary visual cortex were examined after kainic acid lesions of the visual claustrum (Sherk and LeVay, 1983). In all the animals studied, there was a marked decrease in the incidence of "end-stopped" receptive fields. End-stopping is the property by which the re-

Received Dec. 23, 1985; revised Mar. 28, 1986; accepted May 12, 1986

I thank Dr. W. M. Cowan for use of the electron microscope facility, Dr. B. McGuire, Dr. H. Sherk, and S. McConnell for comments on the manuscript, and N. Goodknight for secretarial assistance. This study was supported by National Institutes of Health Grant EY05551.

Correspondence should be addressed to Simon LeVay, Ph.D., Salk Institute, P.O. Box 85800, San Diego, CA 92138-9216.

Copyright (c) 1986 Society for Neuroscience $0270-6474 / 86 / 123564-12 \$ 02.00 / 0$ sponses of some cortical neurons, previously called "hypercomplex cells" by Hubel and Wiesel (1965), are suppressed as the length of the stimulating slit of light is extended bcyond some optimal value. Interestingly, neurons in the visual claustrum behave in a complementary fashion: Their responses to an oriented stimulus increase monotonically with stimulus length, sometimes showing length summation up to $40^{\circ}$ or more-a sizable portion of the animal's entire field of view (Sherk and LeVay, 1981).

These observations suggest that claustral neurons contribute to end-stopping by exerting a length-dependent inhibition on some neurons in the visual cortex. The inhibition might be exerted directly, or it might involve the excitation of inhibitory cortical interneurons. The present study was undertaken to obtain morphological evidence bearing on this question. The claustrocortical axons were labeled by anterograde transport of peroxidase-conjugated WGA, and their terminals, and the structures they contacted, were examined in the EM. The results indicate that the second of the 2 models, in which claustral afferents excite a population of cortical interneurons that in turn inhibit the end-stopped cells, is more likely correct.

Because a novel procedure was employed to demonstrate the laheled afferents in thin sections, a better characterized set of afferents, those arising in the lateral geniculate nucleus, was also examined by the same method. The results confirm and extend earlier work.

\section{Materials and Methods}

\section{$W G A$ injections}

Four adult cats received injections of peroxidase-labeled WGA. Two received unilateral injections into the visual claustrum, 1 a unilateral injection into the lateral geniculate nucleus (LGN), and in 1 cat the claustrum was injected on one side and the LGN on the other. [There is a weak, crossed claustrocortical projection to the region of the 17-18 border (LeVay and Sherk, 1981a), but this was not a concern since the LGN injection was placed so as to produce a projection zone well into area 17 proper.]

Techniques for recording and injections have been described previously (LeVay and Sherk, 1981a). In brief, recordings were first made with a tungsten electrode in the paralyzed, barbiturate-anesthetized animals, in order to locate the desired injection site within the LGN or claustrum. The electrode was then replaced with a glass micropipette containing $1 \% \mathrm{WGA}$ in $0.9 \% \mathrm{NaCl}$. Recordings were continued until the desired site was relocated, and a volume of $0.2 \mu l$ was injected by air pressure over about $5 \mathrm{~min}$. The injections into the LGN were made at a position in the field map where the projection lines run vertically (on the horizontal meridian at an azimuth of $8^{\circ}$ ), and the injected volumes were divided between laminae $\mathrm{A}$ and $\mathrm{A} 1$. The claustral injections were made near the ventral border of the visual region, within the representation of the area centralis. Because of the small size of the visual claustrum, however, such injections effectively label almost the entire set of claustral axons projecting to visual cortex.

After a $2 \mathrm{~d}$ survival, the animals were reanesthetized, intubated, and connected to a respirator. The chest was opened and the descending aorta clamped off. One liter of ice-cold $0.1 \mathrm{~m}$ phosphate buffer, $\mathrm{pH} 7.2$, 
was perfused rapidly through the left ventricle, using pressure from a compressed-air cylinder. This was followed by 2 liters of $1 \%$ paraformaldehyde, $2 \%$ glutaraldehyde, and $2 \%$ sucrose in the same buffer. Blocks containing the injection sites and the visual cortex were sectioned at $100 \mu \mathrm{m}$ on a vibrating microtome and collected in $0.1 \mathrm{M}$ phosphate buffer, $\mathrm{pH}$ 6.0. The sections were reacted for demonstration of peroxidase in a solution of $0.25 \%$ ammonium molybdate, $0.005 \%$ tetramethylbenzidine (TMB; Sigma), and $0.01 \%$ hydrogen peroxide in $0.1 \mathrm{M}$ phosphate buffer, $\mathrm{pH}$ 6.0. The procedure followed the protocol of Olucha et al. (1985), except that the water rinses were omitted and the reaction was carried out for $1-5 \mathrm{hr}$ at $4^{\circ} \mathrm{C}$ without further addition of peroxide. Blocks of tissue containing terminal labeling in area 17, as well as blocks containing labeled fibers in the white matter, were cut out under a dissecting microscope and processed for electron microscopy according to the following schedule (all steps at $4^{\circ} \mathrm{C}$ ):

$1 \% \mathrm{OsO}_{4}$ in $0.1 \mathrm{M}$ phosphate buffer, $\mathrm{pH} 6.0,30 \mathrm{~min}$

buffer rinse, $5 \mathrm{~min}$

$50 \%$ alcohol, $2 \mathrm{~min}$

$70 \%$ alcohol, $2 \mathrm{~min}$

$90 \%$ alcohol, $2 \mathrm{~min}$

$100 \%$ alcohol, $2 \mathrm{~min}$

propylene oxide, $5 \mathrm{~min}$

propylene oxide-EM embedding medium (1:1), $30 \mathrm{~min}$

embedding medium, $1 \mathrm{hr}$

The embedding medium consisted of epoxy resin (TAAB 812), dodecenyl succinic anhydride, and methyl nadic anhydride in the weight ratios 2:0.75:1, with 1\% DMP-30 accelerator. Curing was carried out at $70^{\circ} \mathrm{C}$ for $36 \mathrm{hr}$. Rapid processing was required up to the time when the blocks were polymerized, in order to prevent dissolution of the peroxidase reaction product.

Semithin sections were cut and stained with toluidine blue. Using these as a guide, the blocks were trimmed to include single cortical layers, and ultrathin (silver or pale gold) sections were cut and stained with $2 \%$ aqueous uranyl acetate $(15 \mathrm{~min})$ and $0.1 \%$ lead citrate in 0.1 $\mathrm{M} \mathrm{NaOH}(3 \mathrm{~min})$.

Control blocks of tissue from cortical regions away from the projection zones were processed in similar fashion. Other blocks from the region of the projection zones were processed omitting the peroxidase reaction.

Some of the $100 \mu \mathrm{m}$ sections were counterstained with neutral red for light microscopy, dehydrated, and mounted in Permount. The counterstaining helped to stabilize the reaction product; however, fading in the unstained sections could be largely prevented by storage in the dark at $-20^{\circ} \mathrm{C}$.

\section{PHA-L injections}

Two cats received unilateral injections of unlabeled Phaseolus leucagglutinin (PHA-L) into the visual claustrum. Procedures closely followed the protocol of Gerfen and Sawchenko (1984). In brief, after locating the desired recording site as described above, the lectin was ejected over $15 \mathrm{~min}$ by iontophoresis. The animals were allowed to survive for 2 weeks and were then perfused with $4 \%$ paraformaldehyde in $0.1 \mathrm{M}$ phosphate buffer, $\mathrm{pH} 6.5$, followed by $4 \%$ paraformaldehyde and $0.05 \%$ glutaraldehyde in $0.1 \mathrm{~m}$ borate buffer, $\mathrm{pH} 9.5$. Frozen $20 \mu \mathrm{m}$ sections through the injection site and the projection zone in area 17 were processed for immunohistochemical detection of the lectin, using goat antiPHA primary antiserum (Vector) at a dilution of 1:1000, followed by biotinylated rabbit anti-goat IgG and an avidin-biotin-HRP complex (Vector). Sections were then reacted with diaminobenzidine and $\mathrm{H}_{2} \mathrm{O}_{2}$ for $1 \mathrm{hr}$, and mounted on slides. The peroxidase reaction product was intensified with $0.01 \% \mathrm{OsO}_{4}$. Some sections were counterstained with cresyl violet.

Partial reconstructions of labeled terminal arborizations in area 17 were made by tracing labeled processes in serial $20 \mu \mathrm{m}$ sections with $\times 40$ oil-immersion optics and a drawing tube.

\section{Results}

\section{Geniculate afferents}

The WGA injection sites in the LGN involved laminae A and $A 1$, with some spread to lamina $C$ and the perigeniculate nucleus in both cases. The projection zones in area 17 resembled those seen by autoradiography after ${ }^{3} \mathrm{H}$-proline injections of the geniculate A laminae (LeVay and Gilbert, 1976): There was a major band of label in layer 4 and a lesser band in layer 6 . In addition, however, layer 6 contained numerous retrogradely labeled somata, those of the cells of origin of the corticogeniculate pathway (Gilbert and Kelly, 1975). Labeling extended only short distances into the dendrites of these cells.

For electron microscopy, thin sections were cut from blocks trimmed to include only layer 4 or layer 6 , and stained with uranyl acetate and lead citrate. In these sections, it was found that the peroxidase reaction product took the form, not of electron-dense deposits, but of holes. Examples of these holes in the sections are apparent in most of the figures shown in this paper. From their extreme electron-lucency and refractile edges, it was evident that these holes represented the absence not only of tissue but also of the embedding medium. Evidently the crystalline reaction product had not been penetrated by the embedding medium; when the sections were exposed to aqueous media during sectioning and counterstaining, the crystals dissolved, leaving voids. In confirmation of this, sections that had been picked up rapidly from the microtome trough and examined without counterstaining still contained reaction product in the form of electron-dense deposits, which often were already partially dissolved.

Sections from control tissue that had not been subjected to the peroxidase incubation contained no holes, except for those caused by knife scratches. The latter were readily recognizable, since they formed confluent and perfectly straight linear arrays and did not respect any tissue boundaries. In sections of peroxidase-reacted blocks taken from areas of cortex away from the projection zones, the only holes seen were associated with erythrocytes that had not been flushed out during the perfusion, or occasionally with vascular pericytes. It was concluded that the holes in the neural tissue indicated the location of tracer transported from the injection sites. Structures containing such holes will therefore be referred to as labeled.

In both layers 4 and 6 , a substantial fraction of the labeled structures consisted of preterminal axons, both myelinated and unmyelinated. Examples are shown in Figure $1 A$, which is from layer 4 . The myelinated axons were highly variable in diameter, but the unmyelinated axons, which probably represent the bouton-bearing portions of the axonal arborizations (Ferster and LeVay, 1978), were uniformly fine $(<0.5 \mu \mathrm{m})$.

In layer 4, most of the remaining label was found in axon terminals (Fig. 1, $B-E$ ). These terminals were variable in size, but always formed synapses of type 1 (Colonnier, 1968; Gray, 1959; LeVay, 1973). The features of this type of synapse used for identification in the present study were the presence of synaptic vesicles $45-50 \mathrm{~nm}$ in diameter and a synaptic contact with a marked postsynaptic membrane opacity. Type 2 synaptic terminals, none of which was labeled in these experiments, contained smaller $(30-35 \mathrm{~nm})$ vesicles and formed synaptic contacts in which there was little or no postsynaptic density. (The difference in vesicle size is illustrated in Fig. 8.) Flattened vesicles were not observed with the fixation conditions employed here.

Of those labeled terminals that formed a synapse in the plane of section, the great majority contacted dendritic spines (Fig. 1, $B, C$ ). The spines either lacked recognizable contents or contained membranous elements of the spine apparatus. A smaller number of labeled terminals contacted the shafts of dendrites, which were variable in diameter and generally contained mitochondria or microtubules (Fig. $1, D, E$ ).

Labeled axon terminals were also found in layer 6. As in layer 4 , these all formed type 1 synapses, and the majority contacted dendritic spines (Fig. $1 F$ ). Besides this terminal labeling, a considerable amount of label in this layer was located in cell somata and dendrites (not illustrated).

In order to quantify the distribution of label, randomly selected regions from layers 4 and 6 , chosen from several blocks in both cases of geniculate injections, were systematically 

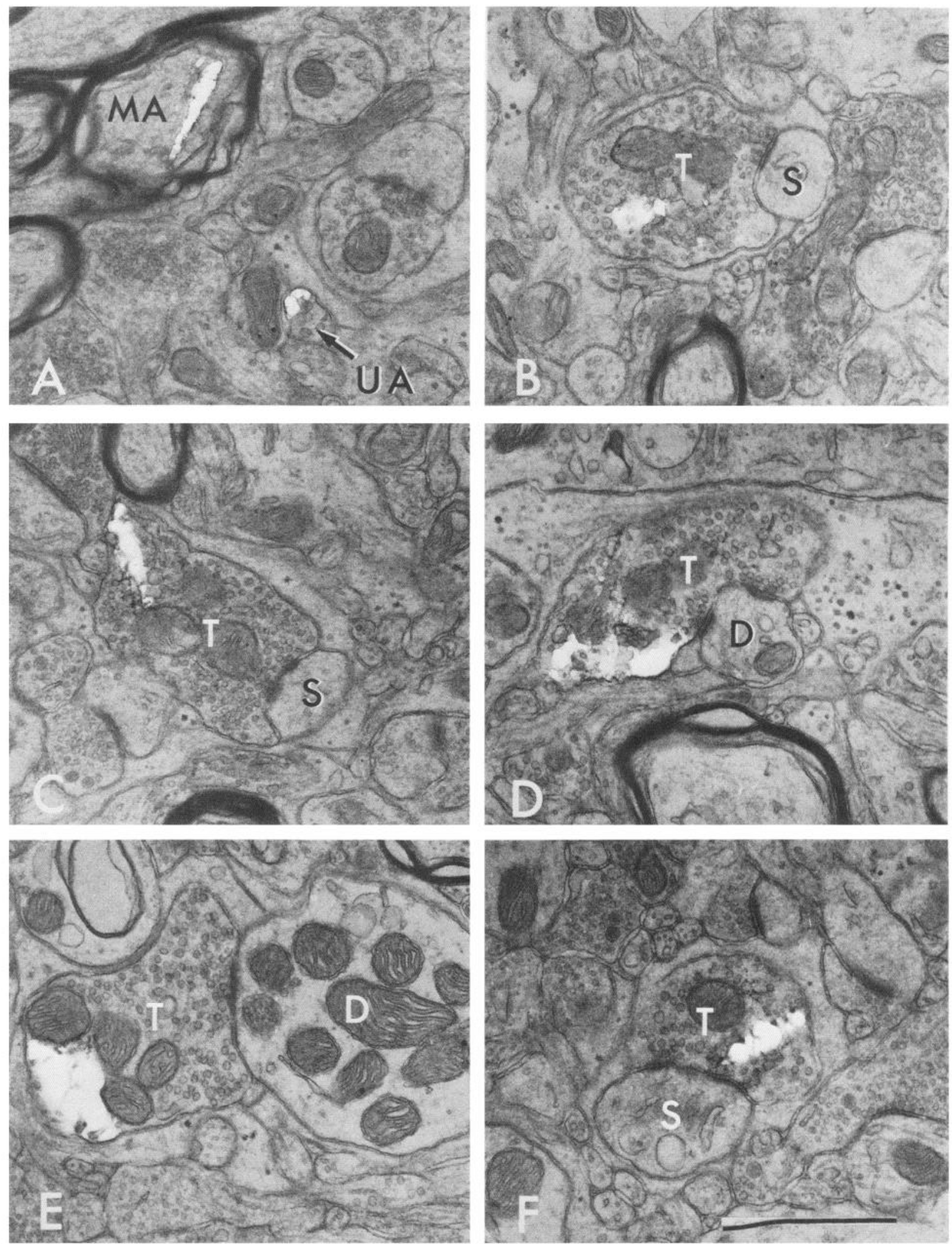

Figure 1. WGA-labeled geniculocortical afferents in area 17. The label takes the form of holes in the sections (white patches), which are left after dissolution of the peroxidase reaction product. $A$, Labeled myelinated axon $(M A)$ and unmyelinated preterminal axon $(U A)$ in layer 4 . $B$ and $C$, Labeled terminal $(T)$-forming synapses on dendritic spines $(S)$, layer 4. $D$, Labeled terminal $(T)$-forming synapse on a fine dendritic shaft $(D)$, layer 4. $E$, Labeled terminal $(T)$-forming synapse on thick dendritic shaft $(D)$, layer $4 . F$, Labeled terminal $(T)$-forming synapse on dendritic spine $(S)$, layer 6. Scale, $1 \mu \mathrm{m}$ for all panels. 


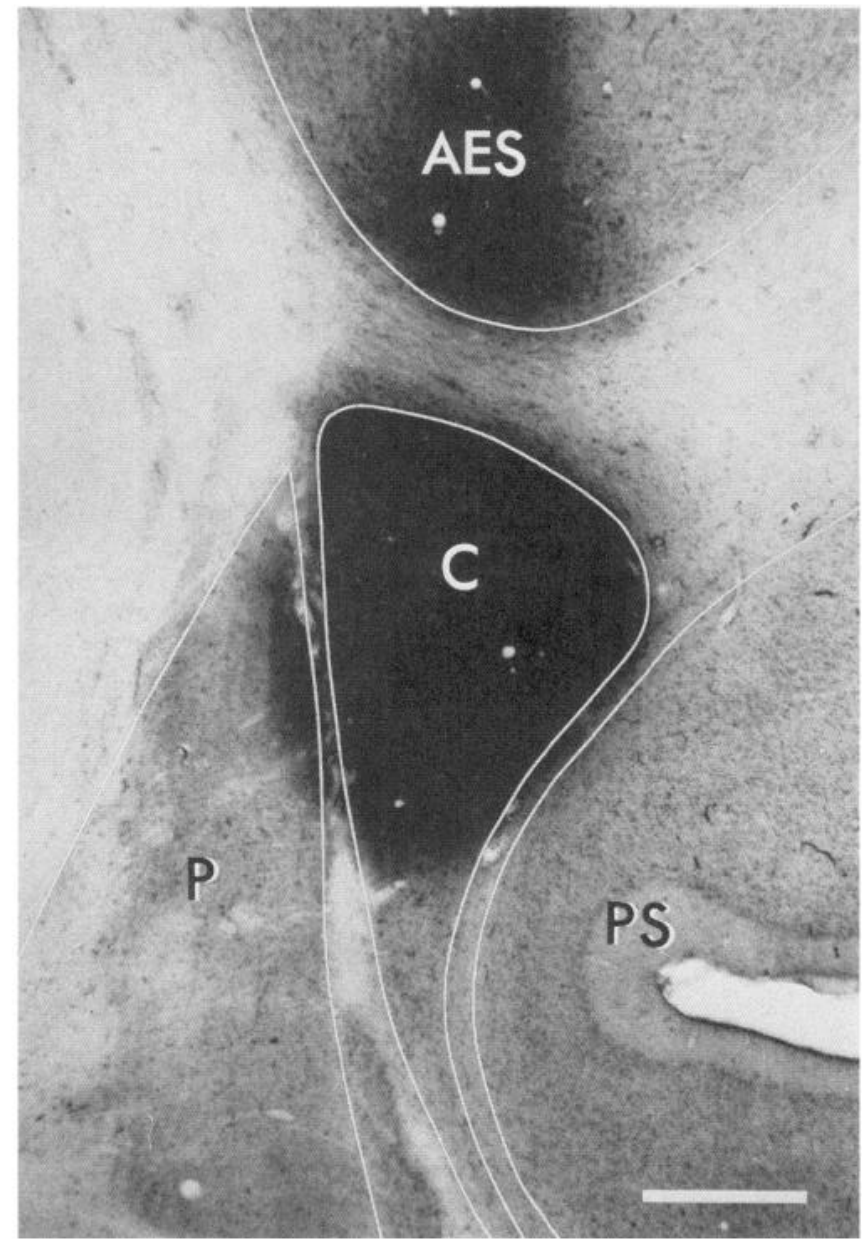

Figure 2. WGA injection site in visual claustrum $(C)$. The section was reacted for $24 \mathrm{hr}$ and hence probably shows the maximum spread of the tracer. There is involvement of a small portion of the putamen $(P)$ and the cortex of the anterior ectosylvian sulcus $(A E S)$. PS, Pseudosylvian sulcus. Coronal section: Dorsal is up and medial is to the left. Scale, $1 \mathrm{~mm}$.

scanned, and the identity of every labeled element was recorded. The results are listed on the left side of Table 1 . In both layers 4 and 6 , about half the labeled profiles were identified as preterminal axons, myelinated or unmyelinated. Another sizable fraction of the profiles $(21 \%$ of the profiles in layer 4 and $11 \%$ in layer 6) could not be identified. It is likely that a large fraction of these profiles were unmyelinated axons; because of their small size they were easily obliterated by the reaction product. Supportive of this interpretation was the observation that the proportions of unidentified profiles and unmyelinated axons tended to rise and fall together in the various samples (compare the first and third lines in Table 1). Preterminal axons, therefore, probably comprised well over half the total labeled profiles.

In layer 4, about a quarter of the labeled profiles were axon terminals; about half of these formed synapses in the plane of section, and those that did preferred dendritic spines to dendritic shafts at a ratio of about $12: 1$. In layer 6 , about $15 \%$ of the labeled elements were axon terminals, and synapses on spines outnumbered those on shafts at a ratio of $8: 1$. The question of how these ratios compared with the overall distribution of synaptic sites in the tissue will be addressed later.

\section{Claustral afferents}

WGA injections: light microscopy. In all 3 cases, inspection of the injection sites revealed heavy labeling of almost the entirety

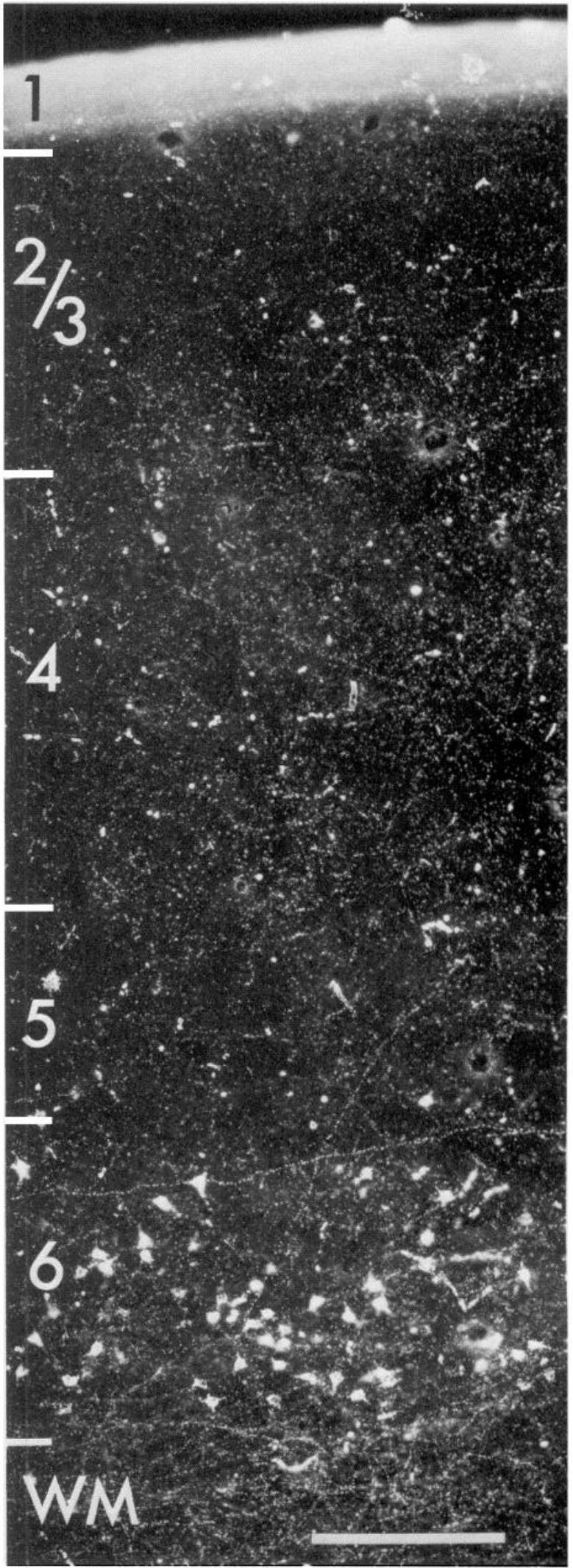

Figure 3. Dark-field micrograph of labeling pattern in area 17 after WGA injection of ipsilateral visual claustrum. The white matter $(W M)$ contains labeled fibers. Retrogradely labeled cell bodies are seen mainly in layer 6. All layers contain fine fibers and "terminal" labeling (fine white dots), but layer 5 is relatively weakly labeled and layer 4 more densely labeled. Label in layer 1 is obscured by scattered light. Scale, $250 \mu \mathrm{m}$. 


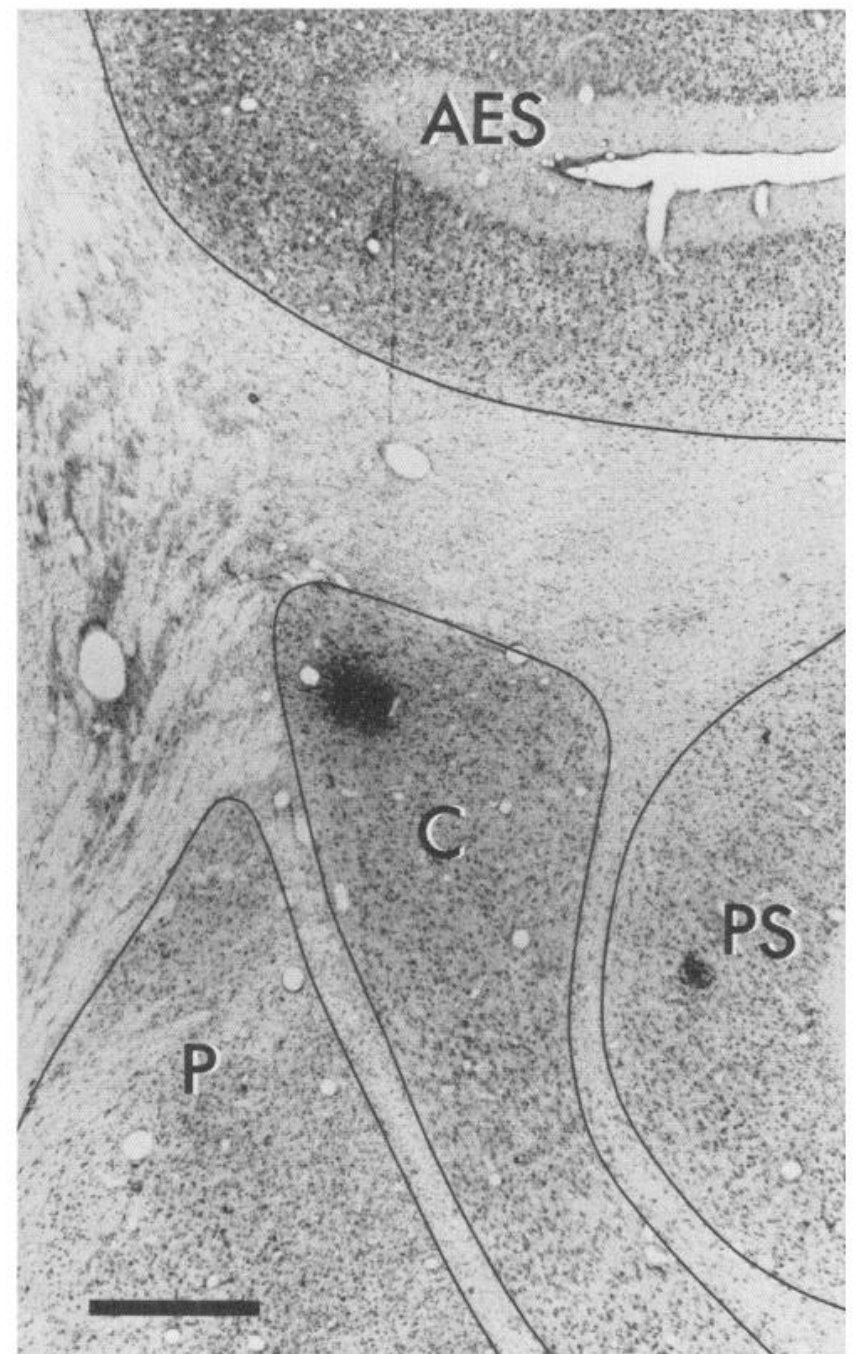

Figure 4. PHA-L injection site (dark patch) in visual claustrum (C). Because single visual field positions are represented along elongated, curved projection lines in the claustrum (LeVay and Sherk, 1981b), a restricted injection such as this will label only a small fraction of all the claustral cells projecting to a given locus in area 17. Orientation of section as in Figure 2. Scale, $1 \mathrm{~mm}$. of the visual claustrum, with slight spread of the tracer to the adjacent portion of the putamen, and more extensive leakage into the overlying cortex of the anterior ectosylvian sulcus (Fig. 2). Neither of these zones has a direct connection with area 17 (LeVay and Sherk, 1981a).

The laminar distribution of label in area 17 is illustrated in Figure 3. Retrogradely labeled cells formed a band within layer 6 , and were occasionally found in other layers, including layer 4. Axonal and granular "terminal" labeling was distributed rather diffusely through all the layers, but layers 1,4 , and 6 were labeled strongly, and layer 5 most weakly. Of the label present in layer 5, a substantial proportion took the form of fine, straggly preterminal axons. The heavy band in layer 1 (which does not show up in Fig. 3 because of light scattering) was seen in all 3 animals, confirming the autoradiographic observations of Olson and Graybiel (1980).

PHA-L injections. Before proceeding to describe the ultrastructural features of the WGA labeling, it would be useful to describe the results obtained with the PHA-L injections, because this lectin forms a Golgi-like filling of axonal arbors (Gerfen and Sawchenko, 1984), allowing one to draw some conclusions about their overall morphology.

The claustral injection sites (Fig. 4) were very small, probably involving only a few hundred cells clustered tightly in a zone well within the boundaries of the nucleus; the zone of labeling in area 17 was similarly confined to the retinotopically corresponding region. The labeled axons were already very fine (not more than $1 \mu \mathrm{m}$ in diameter) as they emerged from the optic radiation, and they rapidly narrowed further as they branched within the cortical gray matter. This fineness (necessitating observation with oil-immersion optics), combined with the obviously very large extent of the arbors, both tangentially and vertically, in the cortex, made the assembly of complete reconstructions from the $20 \mu \mathrm{m}$ sections impossible. Nevertheless, partial reconstructions were made of 7 axons, of which 2 are illustrated in Figure 5. It was clear from these reconstructions that single claustral afferents did not confine their arbors to single cortical layers. Axons were observed that ramified in layers 6 and 4,4 and $2 / 3$, and $2 / 3$ and 1 . It is quite possible that single afferents arborize throughout the cortical thickness, but this could not be established in the present material. Some idea of the lateral spread of the axons is also given by Figure 5 . The deeper of the 2 reconstructed segments had branches in layer 4 that were separated by as much as $1 \mathrm{~mm}$, with a suggestion of clustering.

Table 1. Identity of randomly selected labeled profiles after WGA injections of lateral geniculate nucleus and claustrum

\begin{tabular}{|c|c|c|c|c|c|}
\hline \multirow[b]{2}{*}{ Type of profile } & \multicolumn{2}{|c|}{ Injections of LGN (\%) } & \multicolumn{3}{|c|}{ Injections of claustrum (\%) } \\
\hline & Layer 4 & Layer 6 & Layer 1 & Layer 4 & Layer 6 \\
\hline Unidentified axons & $92(21.1)$ & $25(11.5)$ & $82(33.9)$ & $133(36.6)$ & $60(24.7)$ \\
\hline Myelinated & $104(23.8)$ & $84(38.5)$ & - & $5(1.4)$ & $22(9.1)$ \\
\hline Unmyelinated & $117(26.8)$ & $30(13.8)$ & $105(43.4)$ & $142(39.1)$ & $71(29.2)$ \\
\hline \multicolumn{6}{|l|}{ Terminals } \\
\hline No contact & $65(14.9)$ & $15(6.9)$ & $27(11.2)$ & $39(10.7)$ & $12(4.9)$ \\
\hline On spine & $50(11.4)$ & $16(7.3)$ & $26(10.7)$ & $19(5.2)$ & $14(5.8)$ \\
\hline On dendrite & $4(0.9)$ & $2(0.9)$ & $1(0.4)$ & $22(6.1)$ & $2(0.8)$ \\
\hline On soma & - & - & - & $1(0.3)$ & - \\
\hline Somata & - & $22(10.1)$ & - & - & $27(11.1)$ \\
\hline Dendrites & $4(0.9)$ & $22(10.1)$ & - & $1(0.3)$ & $33(13.6)$ \\
\hline Glia & $1(0.2)$ & $2(0.9)$ & $1(0.4)$ & $1(0.3)$ & $2(0.8)$ \\
\hline Total & $437(100.0)$ & $218(100.0)$ & $242(100.0)$ & $363(100.0)$ & $243(100.0)$ \\
\hline
\end{tabular}




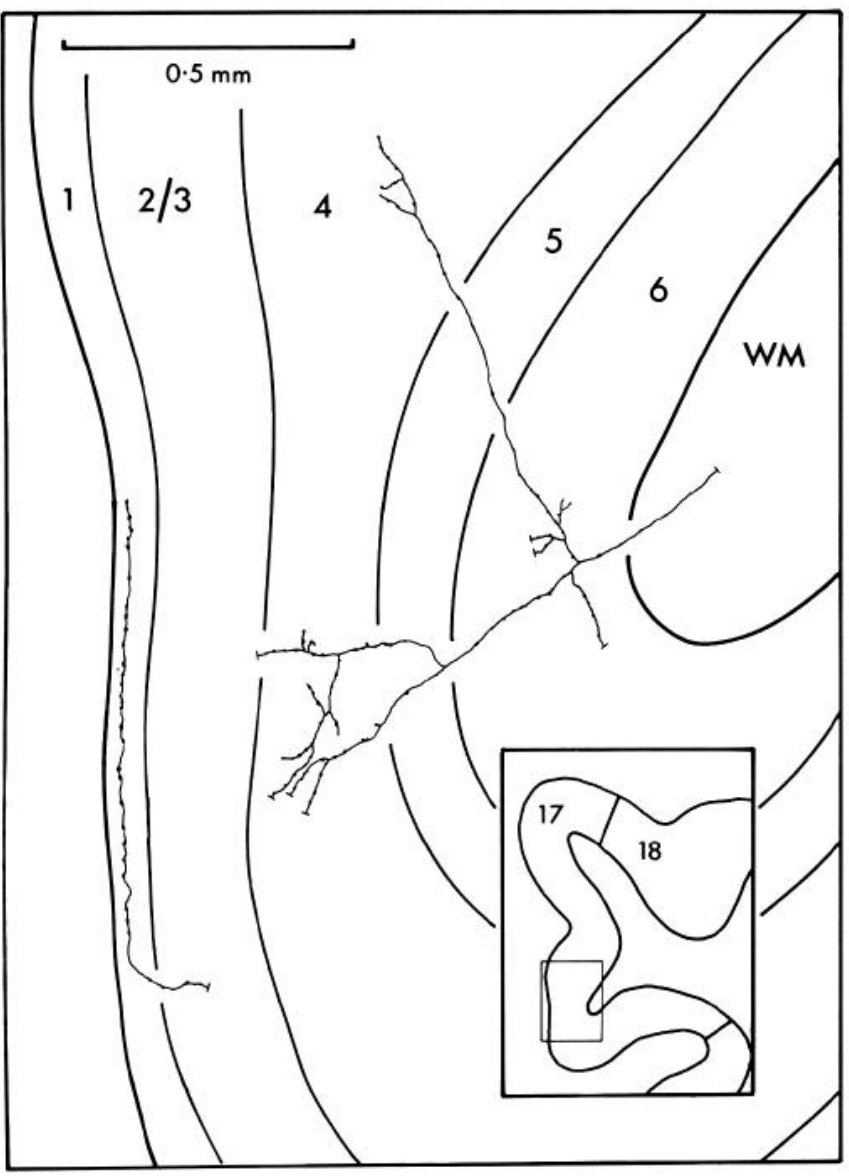

Figure 5. Portions of 2 claustrocortical axons in area 17 , reconstructed from serial $20 \mu \mathrm{m}$ sections reacted with antibodies to PHA-L. The righthand segment, which bears varicosities in layers 6,5 , and 4 , was reconstructed from 13 sections. The 2 terminal clusters in layer 4 are separated by about $0.8 \mathrm{~mm}$. The left-hand segment, which runs tangentially in layer 1 , was reconstructed from 8 sections. The transverse marks at the ends of some branches indicate the limits of the reconstruction. It was not possible to determine whether the 2 segments belonged to the same claustral axon. The thickness of the axons is exaggerated; it was less than $1 \mu \mathrm{m}$ throughout.

The majority of boutons formed by the labeled axons were of the en passage type, with only a minority situated on sidetwigs. Examples are shown in Figure 6. Most of the boutons appeared to be randomly located in the neuropil; in cresyl violetcounterstained sections they were not observed as clustering around cell bodies, although some boutons did touch cell bodies. The boutons in layer 1 were somewhat different: Some of them were larger than any in the deeper layers, and they formed strings arrayed horizontally in the layer. The preference for en passage boutons over side-twigs is a point of similarity with geniculocortical arbors (Ferster and LeVay, 1978; Gilbert and Wiesel, 1979), and distinguishes them from the intracortical collateral arbors of layer 6 pyramidal cells, which carry most of their boutons on side-twigs (McGuire et al., 1984).

$W G A$ injections: electron microscopy. In the EM sections, WGA labeling took the same form that it had after the geniculate injections (i.e., it consisted of holes in the sections), but it was considerably sparser. Another striking difference was that very little label was found in myelinated axons. Those myelinated axons that were labeled consisted of very fine, lightly myelinated fibers, and were located principally in layer 6.

Layers 1, 4, and 6 were examined for labeled synaptic terminals, and such terminals were found in all 3 of these layers.
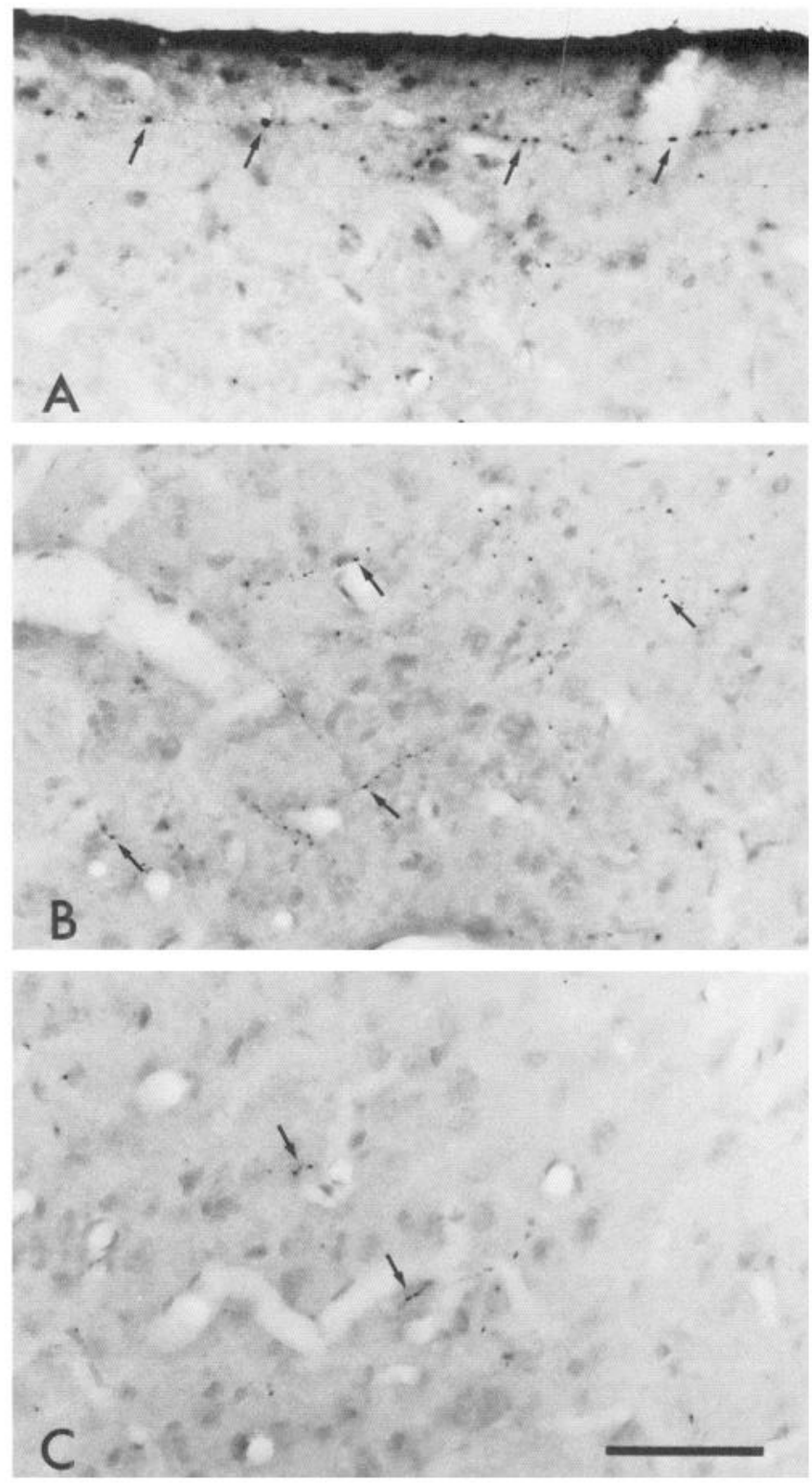

Figure 6. PHA-L-labeled claustral afferents in area 17. A, An axon with relatively large varicosities (arrows) running tangentially in layer 1. The dark staining of the pial surface is an artifact. $B$, Axons with relatively small varicosities (arrows) in layer 4 . $C$, Sparse axons with varicosities in layer 6 . Scale, $50 \mu \mathrm{m}$ for all panels.

All the synaptic terminals were of type 1, the same type as the geniculate terminals.

In layer 4, many of the labeled terminals contacted dendritic shafts. These could be of large or small diameter; 2 examples are shown in Figure 7, $A-D$. In those cases where a significant portion of the dendritic shaft was visible in the section (as in Fig. $7, C, D$ ), it could be seen that other (unlabeled) type 1 synapses contacted nearby regions of the dendrite. Dendritic profiles of this type probably belong to spine-free or sparsely spinous neurons (LeVay, 1973; see Discussion). The other major target of the labeled terminals in layer 4 was dendritic spines (Fig. $7 E$ ). Nothing distinguished these spines from those that were contacted by geniculate afferents. One labeled terminal was observed to contact a neuronal soma (Fig. $7 F$ ).

In layers 1 and 6 , most of the labeled terminals contacted dendritic spines (Figs. 8, $A, B$, and Fig. 9), and a much smaller number contacted dendritic shafts (Fig. $8, C, D$ ). Some of the 

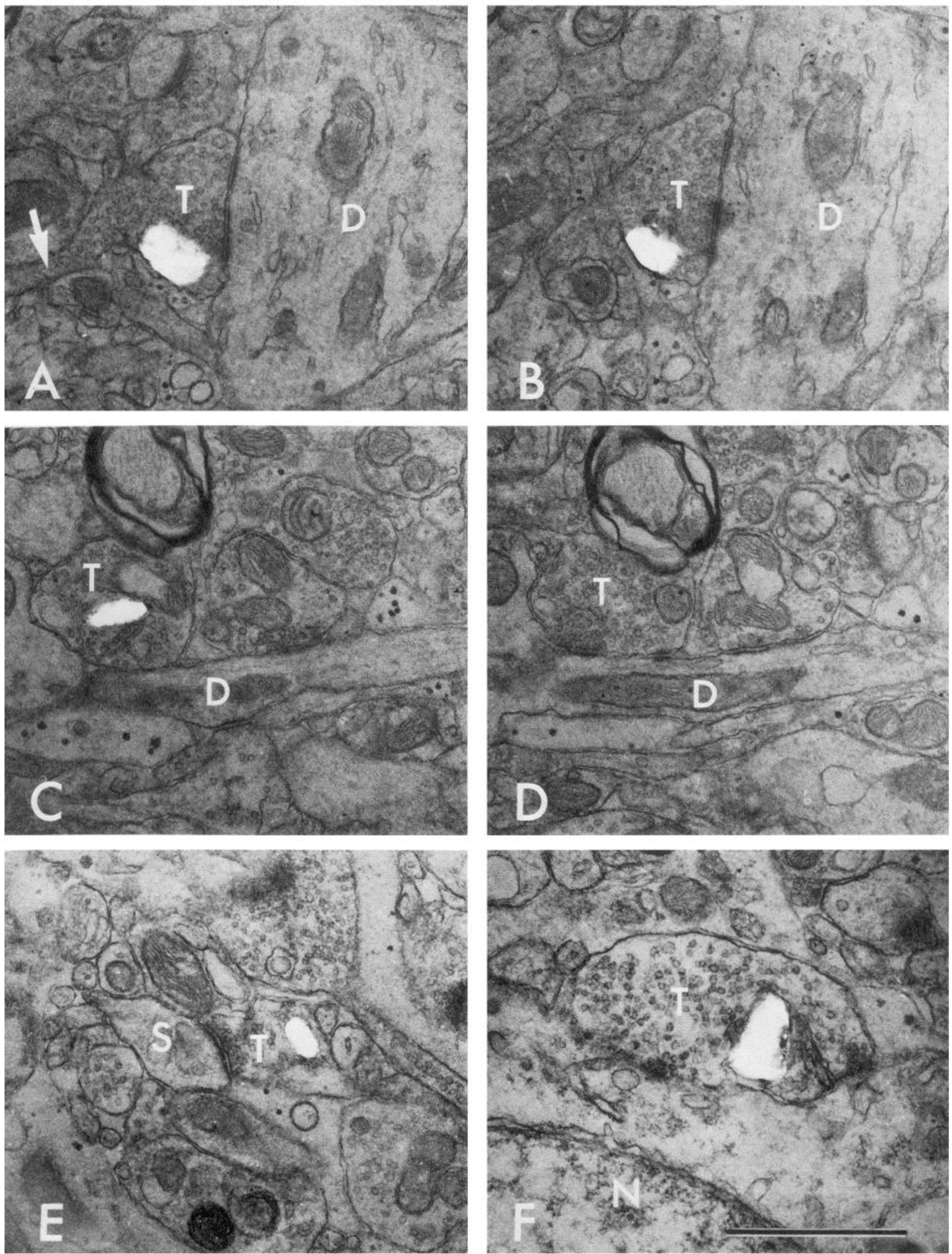

Figure 7. WGA-labeled claustral terminals $(T)$ in layer 4 of area 17. $A, B$, Adjacent sections through a labeled terminal that forms a synapse on a thick dendritic shaft $(D) . C, D$, Nearby sections through a labeled terminal that forms a synapse on a fine dendritic shaft $(D)$. The label is present only in $C$, the synapse only in $D$. $E$, Small labeled terminal that forms a synapse on a dendritic spine $(S)$. $F$, Labeled terminal that forms a synapse on a cell body ( $N$, nucleus). Scale, $1 \mu \mathrm{m}$ for all panels. 

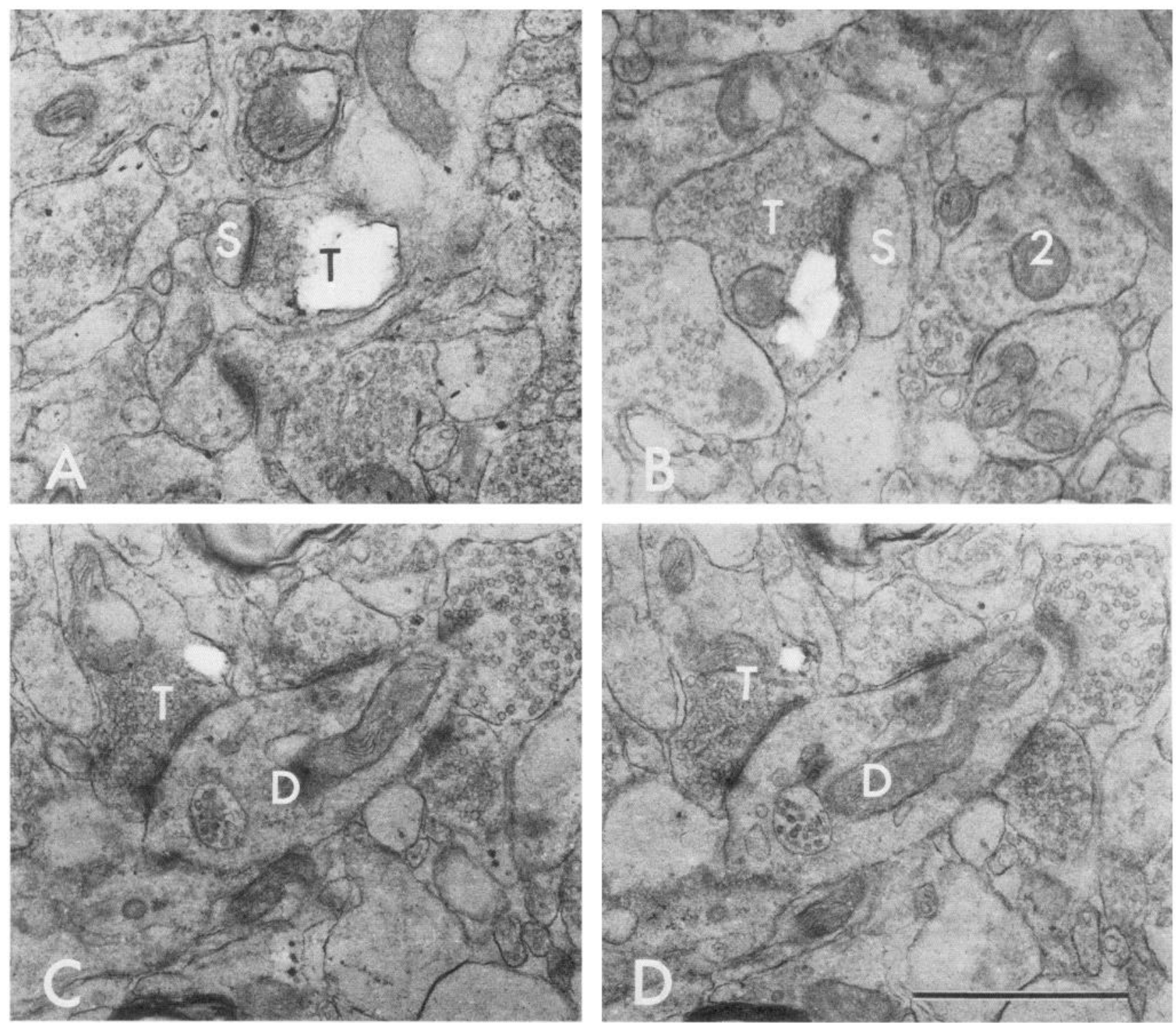

Figure 8. WGA-labeled claustral terminals $(T)$ in layers 1 and 6 of area 17. A, Small labeled terminal that forms a synapse on a dendritic spine $(S)$, layer 1. B, Labeled terminal forming synapse on spine (S), layer 6 . Note also an unlabeled type 2 terminal, recognizable on the basis of its smaller synaptic vesicles. It forms a synapse on a dendritic shaft, above right, but the synaptic contact is sectioned obliquely. $C, D$, Adjacent sections through a labeled terminal that forms a synapse on a dendritic shaft $(D)$. Scale, $1 \mu \mathrm{m}$ for all panels.

terminals in layer 1 were of a larger size than those observed in other layers, just as light-microscopic examination of PHA-L preparations had suggested (see above).

The identity and proportions of the labeled elements in layers 1,4 , and 6 were examined by a systematic scanning of randomly selected regions from 2 of the 3 available cases. The findings (Table 1, right side) confirmed the high proportion of label in unmyelinated axons and in unidentified profiles (which, as mentioned above, may also largely consist of unmyelinated axons). Together, these 2 categories comprised about three-quarters of the total labeled profiles in layers 1 and 4 . Of the labeled terminals, about one-half formed a synapse in the plane of section. In both layers 1 and 6, the great majority of these synapses were formed with dendritic spines, but in layer 4 there were about equal numbers of synapses on spines and on dendritic shafts.

Those terminals that made no synaptic contacts in the plane of section probably did form synapses outside of the section plane. In cases where such terminals were followed through serial sections, synaptic contacts could usually be found, as illustrated in Figures 7, C, D, and 9. Thus there was no reason to suspect that claustral axons had nonsynaptic release sites, as has been suggested in the case of noradrenergic afferents to the cortex (Descarries et al., 1977; but see Molliver et al., 1982). It would require further study, however, to be certain on this point.

\section{Statistical comparisons}

A comparison was made between the distributions of geniculate and claustral terminals and the overall synaptic population, and each other, by scanning samples of tissue from layers 1,4 , and 6 of 2 animals; about 100 synapses were randomly selected from each layer (regardless of presence or absence of label) and their postsynaptic elements identified. Table 2 gives the resulting distributions, as well as the distributions of the structures with which labeled geniculate and claustral terminals synapsed (extracted from Table 1).

In layer 4 , the total synaptic population consisted of about 

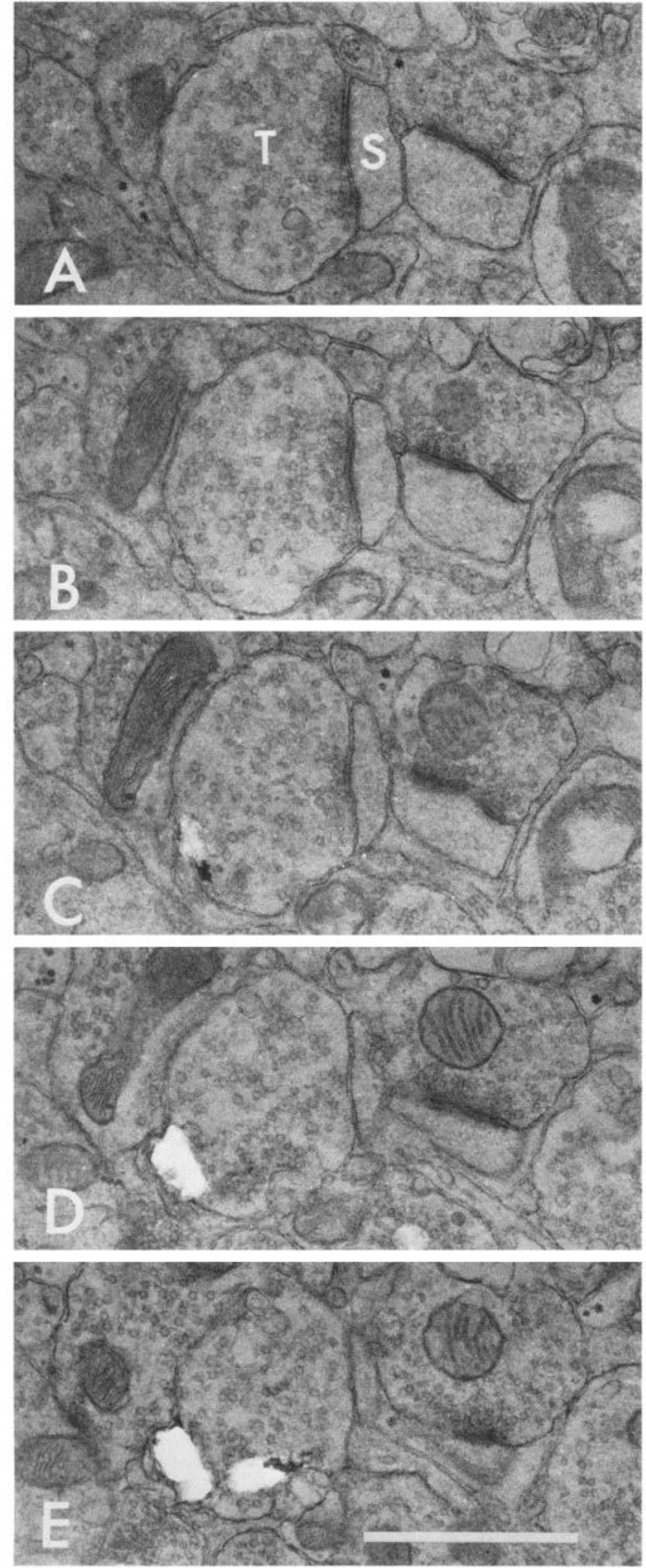

Figure 9. Five serial sections $(A-E)$ through a labeled claustral terminal $(T)$ in layer 1 . It contacts a dendritic spine $(S)$. The synaptic contact is seen in $A$ and $B$, the label in $C-E$. Scale, $1 \mu \mathrm{m}$.
Table 2. Proportion of all synapses, labeled geniculate synapses, and labeled claustral synapses on dendrite spines, dendritic shafts, and somata

\begin{tabular}{cccc} 
& $\begin{array}{l}\text { All synapses } \\
(\%)\end{array}$ & $\begin{array}{l}\text { Geniculate } \\
\text { synapses (\%) }\end{array}$ & $\begin{array}{l}\text { Claustral } \\
\text { synapses (\%) }\end{array}$ \\
\hline Layer 1 & & & \\
Spines & $87(86)$ & & $26(96)$ \\
Shafts & $14(14)$ & & $1(4)$ \\
Layer 4 & & & $19(45)$ \\
Spines & $61(47)$ & $50(93)$ & $22(53)$ \\
Shafts & $68(52)$ & $4(7)$ & $1(2)$ \\
Somata & $1(1)$ & - & $14(88)$ \\
Layer 6 & & & $2(12)$ \\
Spines & $62(58)$ & $16(89)$ & - \\
Shafts & $39(37)$ & $2(11)$ & - \\
Somata & $5(5)$ & - & \\
\hline
\end{tabular}

half synapses on dendritic spines and half synapses on dendritic shafts. ${ }^{2}$ Labeled geniculate synapses, on the other hand, preferred spines over shafts at a ratio of 12:1. The difference between the 2 distributions was highly significant $\left(p<0.001 ; \chi^{2}\right.$ test, 2-tailed). Claustral synapses were distributed about equally to spines and shafts. Their distribution did not differ significantly from the overall distribution but was significantly different from the distribution of geniculate synapses $(p<0.001)$.

The relative numbers of geniculate and claustral terminals synapsing on spines and shafts were not normalized for such factors as terminal size, size and localization of reaction product (holes) within the terminals, and length of synaptic contacts. Qualitative inspection suggested that there were no systematic differences in these parameters that could have artefactually produced the large numerical differences between the targets of the 2 sets of afferents.

In layer 6, the overall sample of synapses was mildly biased towards spines over shafts (the ratio was about $3: 2$ ). The samples both of labeled geniculate and claustral terminals were more strongly biased, with ratios of about $8: 1$ in favor of spines over shafts. The geniculate and claustral samples did not differ significantly from each other. The geniculate sample differed significantly from the overall sample $(p<0.05)$, while the difference between the claustral and overall samples just failed to reach significance.

In layer 1 , the overall sample was biased quite strongly towards spines (the ratio was about $6: 1$ ). Of the 27 claustral terminals sampled, all but 1 contacted spines. The difference between the 2 distributions was not significant.

It is clear that claustral terminals have a different pattern of connectivity in layer 4 , where they contact spines and shafts equally, than in either layer 6 or 1 , where spines were strongly preferred. Both these differences were significant (comparing layers 4 and $6, p<0.02$; comparing layers 4 and $1, p<0.001$ ).

\section{Diameter of claustrocortical axons}

Measurements of the diameters of labeled axons in a sample taken from the white matter about two-thirds of the distance from the claustrum to area 17 were made in order to derive an estimate of conduction velocity in the claustrocortical pathway.

\footnotetext{
${ }^{2}$ Beaulieu and Colonnier (1985), in a detailed stereological study of cat cortex, report a higher fraction of axo-spinous synapses in layer 4 . Although their figures may well be closer to the true population values, it seemed appropriate for the statistical analysis to use control samples from the same preparations, and classified in the same way, as the labeled terminals.
} 
The fibers were photographed at a magnification of $\times 7000$ and their diameters measured directly from the negatives. Because the fibers were sectioned obliquely, their profiles formed ellipses in the EM sections; the lesser diameter was therefore used as a measure of true fiber diameter. Of the 36 labeled axons that were randomly selected for photography, 34 were myelinated and 2 were unmyelinated. The myelinated axons had a mean diameter of $0.97 \mu \mathrm{m}(\mathrm{SD}, 0.30 \mu \mathrm{m})$ inclusive of the myelin sheath, and the 2 unmyelinated axons both had diameters of $0.5 \mu \mathrm{m}$. From the calculations of Waxman and Bennett (1972) on the relationship between fiber diameter and conduction velocity, one can estimate that the myelinated claustrocortical axons conduct at a velocity of about $5 \mathrm{~m} \mathrm{sec}^{-1}$. Of course, this estimate may be in error if the axons change diameter during their coursefor example, as a result of repeated branching. It is somewhat higher than the value of $2.4 \mathrm{~m} \mathrm{sec}^{-1}$ derived from latency measurements by Tsumoto and Suda (1982).

\section{Discussion}

This study has provided evidence that afferents to layer 4 of visual cortex arising from the LGN and from the claustrum form the same morphological type of synapse-the type thought to be excitatory in function - but differ considerably in the types of neural elements that they contact. The results suggest that the geniculate afferents predominantly contact spine-bearing neurons such as pyramidal and spiny stellate cells, which contribute to the major interlaminar and output pathways of the cortex. The claustral afferents, on the other hand, appear to have a major input to local-circuit cells, which may be inhibitory in function.

\section{Evaluation of the method}

The use of peroxidase-conjugated WGA as a tracer, combined with molybdate-TMB histochemistry, produces an unusual type of labeling that takes the form of minute voids in the electronmicroscopic sections. They apparently form by dissolution of the crystalline reaction product after sectioning. ${ }^{3}$ While there will doubtless be those willing to dismiss these holes as "negative evidence," the following points may be made in their favor. First, no such holes were seen in control sections, so the background level of labeling appears to be 0 . Second, tissuc preservation, while not comparable to conventionally prepared EM material, is superior to that obtainable with the earlier TMB protocols. Third, the extreme contrast between the holes and the remainder of the section allows the holes to be spotted rcadily at low magnification without the use of viewing binoculars. This is of some importance when dealing with a sparse projection such as the claustrocortical pathway. Finally, the method is rapid-sections can be examined within 3-4 d of making the injection.

The major drawback of the method is that, if single sections are examined, not every labeled bouton will actually be seen to contain a hole. This is because the holes are smaller than the boutons, so that some sections passing through the bouton will miss the hole. For this reason, it is not possible to estimate the fraction of the total population of boutons that is labeled without a statistical analysis based on measurements of the sizes and shapes of the boutons and the holes. In an autoradiographic study by LeVay and Gilbert (1976), the fraction of boutons in layer 4 reported as labeled after an injection of ${ }^{3} \mathrm{H}$-proline into

\footnotetext{
${ }^{3}$ In a subsequent study of the afferents from the thalamic intralaminar nuclei to area 17 (Cunningham and LeVay, 1986) it was found that the molybdate-TMB reaction product can be rendered insoluble by the same stabilization step as that recommended by Henry et al. (1985) for stabilization of the product of the original TMB reaction (Mesulam, 1978). This procedure prevents any loss of reaction product during dehydration, but results in labeling that is harder to detect at low magnification.
}

the LGN was $28 \%$. In the present study, the comparable figure was about 5\%. While the earlier figure may be an overestimate (no procedure was employed to subtract background labeling), it is clear that any simple attempt to determine the incidence of labeled boutons with the present method will lead to an underestimate of their numbers.

A second potential drawback is that the tracer employed is transported retrogradely as well as anterogradely. This raises the possibility that some of the labeled boutons might actually belong to recurrent collaterals of the corticogeniculate or corticoclaustral projection neurons, rather than to the afferents. While this possibility cannot be discounted, there are reasons to believe that it is not a major confounding factor. First, the recurrent collaterals of the corticoclaustral projection neurons are restricted to cortical layer 6 (Katz et al., 1984; LeVay and Sherk, 1981a), and therefore could not be involved in producing the observed labeling pattern in layers 4 and 1 . Second, the recurrent collaterals of corticogeniculate projection neurons, though they do ascend to layer 4 , mostly make different synaptic contacts from those actually observed after geniculate injections (see below).

\section{Preterminal axons}

One striking feature of the labeling patterns produced by both geniculate and claustral injections was the large fraction of label present in preterminal axons. Labeled axons generally outnumbered labeled terminals by about $2: 1$, even in layer 4 . Presumably the amount of label in these structures simply reflected the fraction of the entire axonal volume consisting of preterminal segments. In the case of the geniculate injections, these axons comprised myelinated and unmyelinated fibers in about equal proportions. This is consistent with earlier work showing that geniculocortical afferents have very elaborate, partially myelinated, preterminal plexuses (Ferster and LeVay, 1978; Gilbert and Wiesel, 1979; Humphrey et al., 1985). By contrast, most of the claustral afferents appeared to lose their myelin sheaths as soon as they cnter laycr 6-just a few myclinated axons were labeled in layer 4 , and none in layer 1 . Nevertheless, their unmyelinated arbors may well be as elaborate and extensive as the arbors of geniculate neurons, insofar as one can judge from the fragmentary reconstructions obtained with the PHA-labeling method.

\section{Synaptic connections}

Both the geniculate and claustral afferents appeared to form type 1 (asymmetric) synapses exclusively. This is the type that is thought to be excitatory in function (Uchizono, 1965). As far as the geniculate afferents are concerned, most previous studies have reported that they form only type 1 synapses (Garey and Powell, 1971; LeVay and Gilbert, 1976; McGuire et al., 1984; but see Einstein et al., 1983). This conclusion is consistent with the physiological observation that activation of the geniculocortical afferents leads to monosynaptic excitation of cortical neurons, and not to monosynaptic inhibition (Ferster and Lindström, 1983). It is also consistent with the observation that glutamic acid decarboxylase-immunoreactive neurons in the LGN (presumed GABAergic inhibitory cells) do not project to visual cortex (Fitzpatrick et al., 1984).

The finding that claustral afferents form type 1 synapses is also in line with physiological observations. Tsumoto and Suda (1982) reported that the initial responses of cortical cells to shocks delivered to the claustrum were always excitatory; IPSPs occurred with longer latencies, suggestive of intracortical processing. Claustral projection cells are large, spine-bearing neurons that resemble, aside from their less regular geometry, the pyramidal neurons of the cerebral cortex (LeVay and Sherk, 1981a); the finding that they form type 1 synaptic connections is a further point of similarity, since pyramidal cell axons have been shown to form type 1 synapses wherever they have been 
examined (for visual cortex, see Jones and Powell, 1969; LeVay, 1973; LeVay and Sherk, 1981a; Lund, 1972; McGuire et al., 1984, 1985).

Although both geniculate and claustral axons formed type 1 synapses, they differed in the distribution of their postsynaptic targets, at least in layer 4 . In this layer, the geniculate terminals had a very strong preference (12:1) for dendritic spines over dendritic shafts. Several previous studies have noted this bias towards spines, although the estimated ratios have varied (Garey and Powell, 1971; LeVay and Gilbert, 1976; Winfield and Powell, 1983). The present ratio of $12: 1$ is very close to a recent estimate by McGuire et al. (1984) based on a smaller sample of labeled boutons. This preference for spines implies a selectivity for cortical neurons that possess spine-laden dendrites, namely, pyramidal and spiny stellate cells. The claustral afferents to layer 4 , on the other hand, terminated about equally on spines and dendritic shafts. The neuron class that receives type 1 inputs predominantly onto its dendritic shafts is the spinefree or sparsely spinous neuron (LeVay, 1973). Many, perhaps most, neurons of this class are inhibitory in function, to judge by their immunoreactivity for the GABA-synthetic enzyme glutamic acid decarboxylase (Hendry et al., 1983; Ribak, 1978) and their possession of axons that form type 2 synapses (LeVay, 1973; Peters and Fairén, 1978). Thus, the present evidence suggests that the claustral afferents to layer 4 devote a much larger fraction of their terminals to inhibitory cortical interneurons than do the geniculate afferents. This pattern, however, was seen only in layer 4 ; in layers 6 and 1 , the claustral axons too synapsed selectively on spines.

The functional differences between the 2 sets of afferents suggested by the above findings are only partial and are subject to some uncertainty. The geniculate afferents, for cxample, even if they form relatively few synapses on inhibitory interneurons, are still able to evoke powerful disynaptic IPSPs in many cortical cells (Ferster and Lindström, 1983). Indeed, given that geniculocortical terminals probably greatly outnumber claustrocortical terminals, it is very possible that, in absolute terms, the geniculate afferents make more synapses on spine-free cells than do the claustral afferents. Also, spiny-dendrite cells do receive some type 1 inputs on their shafts (McGuire et al., 1984), and cells of the "spine-free" class have occasional spines. These anomalous synapses might turn out to be important when one considers that the claustral synapses constitute a small minority of the total synaptic population. Some of these uncertainties might be clarified by serial reconstructions, or by combining axon transport and EM immunohistochemical techniques to identify claustral inputs onto GABAergic cells directly.

Another input to layer 4 arises from the recurrent collaterals of layer 6 pyramidal cells - in particular, from those pyramidal cells that send axons to the lateral geniculate nucleus (Baughman and Gilbert, 1981; Gilbert and Wiesel, 1979). These collaterals also form type 1 synapses, but they preferentially make contact with dendritic shafts (McGuire et al., 1984). Thus the claustral afferents are intermediate in their choice of targets between the geniculate axons and the layer 6 cell collaterals.

\section{Functional significance}

What light do these findings throw on the question of how the corticoclaustral loop contributes to the property of end-stopping in visual cortex? In general, they favor a model in which claustral afferents excite a population of cortical interneurons, which, in turn, inhibit end-stopped cells, rather than one in which claustral afferents exert an inhibition directly. But there are complexities that need to be resolved before the matter can be considered settled.

First, even if all the dendritic shafts contacted by claustral afferents do belong to inhibitory interneurons, which is not certain, there still remains a substantial input to dendritic spines, suggesting a direct excitation of pyramidal and/or spiny stellate neurons, the numerically predominant cell types in visual cortex. The role for such an input is unclear. It is of interest, however, that this type of input is the predominant one in layer 6 , because layer 6 possesses few, if any, end-stopped cells (Gilbert, 1977; Sherk and LeVay, 1983), and it is the layer that contains the corticoclaustral projection neurons. It is possible, therefore, that the spine inputs in layer 6 represent a positive feedback that helps to generate the property of pronounced length-summation characteristic of some layer 6 neurons and of claustral neurons.

Second, neurons with the properties appropriate for claustrorecipient interneurons have not yet been described. They should be situated in layer 4 and perhaps also layer $2 / 3$; they should show length-summation up to very high values; and they should probably also be orientation-selective and responsive to stimulation of either eye. Their properties might be modified to some extent by nonclaustral inputs, especially geniculate inputs, but the key property, pronounced length-summation, should be readily demonstrable, and it is this property that has not been reported in the upper cortical layers (see Gilbert, 1977). It is possible that the neuron involved is a small, infrequent cell type. Its properties and connections need to be documented before the corticoclaustral loop can be considered fully explored.

A third puzzling point is the relationship between the corticoclaustral loop and the direct pathway from layer 6 to layer 4 . Gilbert and Wiesel (1979) have speculated that this pathway too might be involved in the generation of end-stopping, and recently Bolz and Gilbert (1986) have obtained direct evidence in support of such a role. As McGuire et al. (1984) have pointed out, such a circuit apparently also demands the existence in layer 4 of an inhibitory intcrncuron with the characteristic of pronounced length-summation. It might be that a single neuronal type serves as the common recipient of the inputs from the claustrum and layer 6 .

The major question, then, is why the cortex has 2 circuits involved in the generation of end-stopping - a short intracortical loop and a much longer loop through the claustrum. One difference between the 2 circuits is that claustral neurons receive convergent inputs from several visual cortical areas, and show summation up to stimulus-length values that are higher, on average, than those of cortical layer 6 cells (Gilbert, 1977; Sherk and LeVay, 1981). Neither claustral cells nor cortical layer 6 cells, however, have been fully characterized in terms of their responses to complex visual stimuli. It is possible, therefore, that the 2 circuits exert their effects in somewhat different conditions of visual stimulation or over different ranges of stimulus lengths. Another possibility is that the contribution to end-stopping is only a minor function or by-product of the corticoclaustral loop, and that its major function in visual processing remains to be discovered.

\section{References}

Baughman, R. W., and C. D. Gilbert (1981) Aspartate and glutamate as possible neurotransmitters in the visual cortex. J. Neurosci. $1: 427$ 439.

Bcaulieu, C., and M. Colonnier (1985) A laminar analysis of the number of round-asymmetrical and flat-symmetrical synapses on spines, dendritic trunks, and cell bodies in area 17 of the cat. J. Comp. Neurol. 231: $180-189$

Bolz, J., and C. D. Gilbert (1986) Generation of end-inhibition in the visual cortex via interlaminar connections. Nature $320: 362-365$.

Carey, R. G., D. Fitzpatrick, and I. T. Diamond (1979) Layer I of striate cortex of Tupaia glis and Galago senegalensis: Projections from thalamus and claustrum revealed by retrograde transport of horseradish peroxidase. J. Comp. Neurol. 186: 393-438.

Carman, J. B., W. M. Cowan, and T. P. S. Powell (1964) The cortical projection upon the claustrum. J. Neurol. Neurosurg. Psychiatry 27: $46-51$. 
Colonnier, M. (1968) Synaptic patterns on different cell types in the different laminae of the cat visual cortex. An electron microscope study. Brain Res. 9: 268-287.

Cunningham, E. T., Jr., and S. LeVay (1986) Laminar and synaptic organization of the projection from the thalamic nucleus centralis to primary visual cortex in the cat. J. Comp. Neurol. (in press).

Descarries, L., K. C. Watkins, and Y. Lapierre (1977) Noradrenergic axon terminals in the cerebral cortex of the rat. III. Topometric ultrastructural analysis. Brain Res. 133: 197-222.

Einstein, G., T. L. Davis, and P. Sterling (1983) IJltrastructural evidence that two types of X-cell project to area 17. A.R.V.O. Abstr. 24: 266.

Fcrstcr, D., and S. LeVay (1978) The axonal arborizations of lateral geniculate neurons in the striate cortex of the cat. J. Comp. Neurol. 182: 923-944.

Ferster, D., and S. Lindström (1983) An intracellular analysis of geniculocortical connectivity in area 17 of the cat. J. Physiol. (Lond.) 342: $181-215$.

Fitzpatrick, D., G. R. Penny, and D. E. Schmechel (1984) Glutamic acid decarboxylase-immunoreactive neurons and terminals in the lateral geniculate nucleus of the cat. J. Neurosci. 4: 1809-1829.

Garey, L. J., and T. P. S. Powell (1971) An experimental study of the termination of the lateral geniculo-cortical pathway in the cat and monkey. Proc. R. Soc. Iond. [Biol.] 179: 41-63.

Gerfen, C. R., and P. E. Sawchenko (1984) An anterograde neuroanatomical tracing method that shows the detailed morphology of neurons, their axons and terminals: Immunohistochemical localization of an axonally transported plant lectin, Phaseolus vulgaris-leucoagglutinin. Brain Res. 290: 219-238.

Gilbert, C. D. (1977) Laminar differences in receptive field properties of cells in cat primary visual cortex. J. Physiol. (Lond.) 268: 391421.

Gilbert, C. D., and J. P. Kelly (1975) The projections of cells in different layers of the cat's visual cortex. J. Comp. Neurol. 163: 81106.

Gilbert, C. D., and T. N. Wiesel (1979) Morphology and intracortical projections of functionally characterized neurons in the cat visual cortex. Nature 280: 120-125.

Gray, E. G. (1959) Axosomatic and axodendritic synapses of the cerebral cortex: An electron microscope study. J. Anat. 93: 420-434.

Hendry, S. H. C., C. R. Houser, E. G. Jones, and J. E. Vaughn (1983) Synaptic organization of immunocytochemically identified GABA neurons in the monkey sensory-motor cortex. J. Neurocytol. 12: 639660.

Henry, M. A., L. E. Westrum, and L. R. Johnson (1985) Enhanced ultrastructural visualization of the horseradish peroxidase-tetramethylbenzidine reaction product. J. Histochem. Cytochem. 33: 12561259.

Hubel, D. H., and T. N. Wiesel (1965) Receptive fields and functional architecture in two non-striate visual areas (18 and 19) of the cat. J. Neurophysiol. 28: 229-289.

Humphrey, A. L., M. Sur, D. J. Uhlrich, and S. M. Sherman (1985) Projection patterns of individual $\mathrm{X}$ - and $\mathrm{Y}$-cell axons from the lateral geniculate nucleus to cortical area 17 in the cat. J. Comp. Neurol. 233: $159-189$.

Jones, E. G., and T. P. S. Powell (1969) Electron microscopy of synaptic glomeruli in the thalamic relay nuclei of the cat. Proc. R. Soc. Lond. [Biol.] 172: 153-171.

Katz, L. C., A. Burkhalter, and W. J. Dreyer (1984) Fluorescent latex microspheres as a retrograde neuronal marker for in vivo and in vitro studies of visual cortex. Nature 310: 498-500.

Kievit, J., and H. G. J. M. Kuypers (1975) Subcortical afferents to the frontal lobe in the rhesus monkey studied by means of retrograde horseradish peroxidase transport. Brain Res. 85: 261-266.

LeVay, S. (1973) Synaptic patterns in the visual cortex of the cat and monkey. Electron microscopy of Golgi preparations. J. Comp. Neurol. 155: $15-42$
LeVay, S., and C. D. Gilbert (1976) Laminar patterns of geniculocortical projection in the cat. Brain Res. 113: 1-19.

LeVay, S., and H. Sherk (1981a) The visual claustrum of the cat. I. Structure and connections. J. Neurosci. 1: 956-980.

LeVay, S., and H. Sherk (1981b) The visual claustrum of the cat. II. The visual field map. J. Neurosci. 1: 981-992.

Lund, R. D. (1972) Synaptic patterns in the superficial layers of the superior colliculus of the monkey (Macaca mulatta). Exp. Brain Res. 15: 194-211.

McGuire, B. A., J.-P. Hornung, C. D. Gilbert, and T. N. Wiesel (1984) Patterns of synaptic input to layer 4 of cat striate cortex. J. Neurosci. 4: 3021-3033.

McGuire, B. A., C. D. Gilbert, and T. N. Wiesel (1985) Ultrastructural characterization of long-range clustered horizontal connections in monkey striate cortex. Soc. Neurosci. Abstr. 11: 17.

Mesulam, M. M. (1978) Tetramethyl benzidine for horseradish peroxidase neurohistochemistry: A non-carcinogenic blue reaction-product with superior sensitivity for visualizing neural afferents and efferents. J. Histochem. Cytochem. 26: 106-117.

Mettler, F. A. (1935) Corticofugal fiber connections of the cortex of Macaca mulatta. The frontal region. J. Comp. Neurol. 61: 509-542. Molliver, M. E., R. Grzanna, H. G. W. Lidov, J. H. Morrison, and J. A. Olschowka (1982) Monoamine systems in the cerebral cortex. In Cytochemical Methods in Neuroanatomy, V. Chan-Palay and S. L. Palay, eds., pp. 225-277, Alan R. Liss, New York.

Narkiewicz, O. (1964) Degenerations in the claustrum after regional ablations in the cat. J. Comp. Neurol. 123: 335-356.

Norita, M. (1977) Demonstration of bilateral claustro-cortical connections in the cat with the method of retrograde axonal transport of horseradish peroxidase. Arch. Histol. Jpn. 40: 1-10.

Olson, C. R., and A. M. Graybiel (1980) Sensory maps in the claustrum of the cat. Nature 288: 479-481.

Olucha, F., F. Martinez-Garcia, and C. Lopez-Garcia (1985) A new stabilizing agent for the tetramethyl benzidine (TMB) reaction product in the histochemical detection of horseradish peroxidase (HRP). J. Neurosci. Methods 13: 131-138.

Peters, A., and A. Fairén (1978) Smooth and sparsely-spined stellate cells in the visual cortex of the rat: A study using a combined Golgielectron microscope technique. J. Comp. Neurol. 181: 129-172.

Ribak, C. E. (1978) Aspinous and sparsely-spinous stellate neurons in the visual cortex of rats contain glutamic acid decarboxylase. $\mathbf{J}$. Neurocytol. 7: 461-478.

Riche, D., and J. Lanoir (1978) Some claustro-cortical connections in the cat and baboon as studied by retrograde horseradish peroxidase transport. J. Comp. Neurol. 177: 435-444.

Sherk, H., and S. LeVay (1981) The visual claustrum of the cat. III. Receptive field properties. J. Neurosci. 1: 993-1002.

Sherk, S., and S. LeVay (1983) Contribution of the cortico-claustral loop to receptive field properties in area 17 of the cat. J. Neurosci. 3: 2121-2127.

Spector, I., J. Hassmannova, and D. Albe-Fessard (1974) Sensory properties of single neurons of cat's claustrum. Brain Res. 66: 39-65.

Tsumoto, T., and K. Suda (1982) Effects of stimulation of the dorsocaudal claustrum on activities of striate cortex neurons in the cat. Brain Res. 240: 345-349.

Uchizono, K. (1965) Characteristics of excitatory and inhibitory synapses in the central nervous system of the cat. Nature 207: 642-643.

Waxman, S. G., and M. V. L. Bennett (1972) Relative conduction velocities of small myelinated and non-myelinated fibres in the central nervous system. Nature (New Biol.) 238: 217-219.

Whitlock, D. G., and W. J. H. Nauta (1956) Subcortical projections from the temporal neocortex in Macaca mulatta. J. Comp. Neurol. 106: $183-212$.

Winfield, D. A., and T. P. S. Powell (1983) Laminar cell counts and geniculo-cortical boutons in area 17 of cat and monkey. Brain Res. 277: 223-229. 